\title{
Field immobilization of Desert Bobcats (Lynx rufus) using a Tiletamine-Zolazepam anesthetic combination
}

\section{Guillermo Romero-Figueroa ${ }^{*}$ \\ (1) 0000-0002-4191-9828 \\ Ricardo Rodriguez-Estrella2 \\ (D) 0000-0003-2470-2050 \\ Luz Adriana Tapia-Cabazos 3 \\ (D) 0000-0001-9747-5464}

'Laboratorio de Manejo y Conservación

de Vida Silvestre, Facultad de Ciencias,

Universidad Autónoma de Baja California,

Ensenada, Baja California Mexico

2 Programa de Planeación Ambiental y Conservación, Centro de Investigaciones Biológicas del Noroeste,

S.C., La Paz,

Baja California Sur, Mexico

${ }^{3}$ Instituto de Investigaciones en Ciencias Veterinarias, Universidad Autónoma de Baja California, Mexicali, Baja California, Mexico

*Corresponding authors:

Email address:

gromero4@uabc.edu.mx

\begin{abstract}
Chemical immobilization is used to minimize stress and pain while safely handling wild animals under field conditions. Eight wild bobcats (Lynx rufus) were immobilized for radio collar fittings between March 2005 and March 2007, using a commercial tiletamine hydrochloride-zolazepam hydrochloride combination (Zoletil ${ }^{\circledR}$ Virbac, Carros, France). Bobcats were captured using soft catch spring traps (Victor No. 3) in the Sonoran Desert of Baja California Sur, Mexico. A mean ( \pm SD) intramuscular total dose of $44.3 \pm 2.9 \mathrm{mg}$ $\left(6.0 \mathrm{mg} \mathrm{kg}^{-1}\right.$ ) produced an induction time of $9 \pm 4.9 \mathrm{~min}$, and a duration of cataleptic anesthesia of $46.5 \pm 11.4 \mathrm{~min}$. No adverse reactions were observed in animals during handling, and telemetry monitoring indicated that all individuals were alive for at least one year after the procedure. The results of this study indicate that use of tiletamine-zolazepam administered at $6 \mathrm{mg} / \mathrm{kg}$ dose is suitable for short-term chemical immobilization of bobcats in the wild.
\end{abstract}

Keywords: Bobcat; Containment; Lynx rufus; Sonoran desert; Zoletil ${ }^{\circledR}$
Published: $\quad 2020-12-18$

(c) Copyright 2020 Guillermo Romero-Figueroa et al. open access $\boldsymbol{\gamma}$

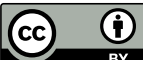

Distributed under Creative Commons CC-BY 4.0

\section{Cite this as:}

Romero-Figueroa G, Rodríguez-Estrella R, Tapia-Cabazos LA. Field immobilization of Desert Bobcats (Lynx rufus) using a Tiletamine-Zolazepam anesthetic combination. Veterinaria México OA. 2020;7(4). doi: 10.22201/fmvz.24486760e.2020.4.812 


\section{Introduction}

Chemical procedures for the immobilization of wildlife minimize stress and pain while animals are being handled. It is a necessary approach in projects that require safety for animals and handlers under field conditions and is frequently used for procedures such as blood drawing and smear sampling to evaluate health status, or telemetry collar fittings for free-ranging population studies. ${ }^{1}$ Restraint procedures are especially important in studies attempting to assess the effects of changes in the ecosystems and habitat fragmentation due to human activities. Research in this area is also essential to implement optimal conservation strategies for top-order predators such as carnivorous mammalian species. Wild mammal studies regularly report the effects of different sedatives used for immobilization. ${ }^{2-9}$ However, documentation on the efficacy and comfort levels associated with their use is still lacking. This information can be essential since both animal handling and the use of chemicals often have an adverse confounding post-handling impact related to changes in normal animal activity, which may lead to biased research results. Moreover, the post-sedation survival data of individuals has been seldomly reported. ${ }^{10-13}$

For the Felidae carnivore family, the most commonly used sedatives are dissociative anesthetics such as cyclohexamines, which include hydrochlorides of ketamine, phencyclidine and tiletamine.,13,14-16 Cyclohexamines are highly effective in a wide range of animal species, as they have a high therapeutic index, and minimal cardiovascular and respiratory effects. ${ }^{17}$ Rarely reported disadvantages of these chemicals are sudden induction and recovery, little muscle relaxation, and occasional prompting of seizures and excessive salivation. ${ }^{17}$ To minimize the advent of these negative effects, cyclohexamines are commonly combined with tranquilizers such as xylazine and zolazepam hydrochlorides or acepromazine maleate. ${ }^{17}$

A combination of ketamine chloride $(100 \mathrm{mg} / \mathrm{ml})$ and xylazine chloride $(20 \mathrm{mg} / \mathrm{ml})$ is often used to immobilize felids. ${ }^{14,18-21}$ Nonetheless, the ketamine-xylazine combination has been shown to cause heart and respiratory distress during anesthesia. ${ }^{22}$ Also, there have been reports of Iberian lynx (Lynx pardinus) experiencing seizures. ${ }^{23}$

Tiletamine is a dissociative anesthetic agent that falls under the drug category of NMDA receptor antagonists and is chemically related to ketamine. Since it does not provide adequate muscle relaxation by itself, it is generally combined with zolazepam, to achieve sufficient muscle relaxation during deep surgical anesthesia. The cranial and spinal nerve reflexes remain however active (which must not be confused with inadequate anesthesia), and both coughing and swallowing, as well as plantar and palpebral reflexes are also maintained. ${ }^{24}$

Zoletil $^{\circledR}$ (Virbac, Carros, France) is a commercial presentation of a tiletamine-zolazepam combination (containing $250 \mathrm{mg}$ of each anesthetic drug), that once reconstituted with $5 \mathrm{ml}$ sterile water, results in an injectable $100 \mathrm{mg} / \mathrm{ml}$ solution. The use of this anesthetic preparation has been reported as safe for many wild species, including lions and leopards, ${ }^{25}$ polar bears, ${ }^{26}$ wild ocelots, ${ }^{13}$ American black bears, ${ }^{27}$ American badgers, ${ }^{28}$ and South American coatis. ${ }^{29}$ Induction time was found to be short in all of these species, a good smooth muscle relaxation was achieved during anesthesia, recovery was smooth, and minimum negative effects on breathing and salivation were reported. Information on the use of these chemicals also exists for felids, however particular data for their use during immobilization of wild bobcats (Lynx rufus) under extreme weather conditions in desert areas, 
such as the Sonoran Desert, are not well known. Desert bobcats are classified as a high stress species, due to the extreme demands imposed on individuals to obtain water and prey. Consequently, handling of these animals can be hazardous since sedation causes further stress. For this work, bobcats were captured and sedated for fitting of telemetry collars as part of a study that evaluates the effects of anthropogenic habitat fragmentation on daily activities of wild individuals. This paper presents information on the use of a tiletamine-zolazepam commercial combination regarding immobilization effects, as well as induction, maintenance, recovery, and inability times during anesthesia, to determine suitability as a protocol for bobcat sedation under field conditions.

\section{Materials and methods Study area}

The study was conducted in the southern portion of the Baja California peninsula in the Santo Domingo valley, Mexico (Valle de Santo Domingo, 24 $55^{\prime} 49.64^{\prime \prime} \mathrm{N}$, $111^{\circ} 37^{\prime} 40.28^{\prime \prime} \mathrm{W}$ and $\left.25^{\circ} 23^{\prime} 46.82^{\prime \prime} \mathrm{N}, 111^{\circ} 50^{\prime} 34.11^{\prime \prime} \mathrm{W}\right)$. The climate is dry, with an average annual temperature of $22.7^{\circ} \mathrm{C}^{30}$ and an average rainfall of 165 $\mathrm{mm} /$ year. ${ }^{31}$ Vegetation is dominated by relatively dense xerophytic shrubland, with typical desert plants such as columnar cacti (Pachycereus pringlei), creosote bush (Larrea tridentata), Adam's tree (Fouquieria diguetii), and mesquite (Prosopis sp.), among other species. ${ }^{32}$

\section{Animals and immobilization procedure}

Eight adult bobcats were captured ( 4 females and 4 males) using snare traps with plastic protection (Victor No. 3, soft catch spring trap) to minimize harm. ${ }^{33,34}$ Hare and feathered chicken carcasses and sardines were used as baits for capture. Traps were prepared in the afternoon and checked every morning for caught individuals.

Once caught, bobcats were immobilized while inside their holding crates, using a pole syringe that allowed for distance intramuscular injection in the hindquarters of the of tiletamine zolazepam (1:1) commercial combination.

Before injection of the sedative, health status of each individual was assessed by observation of external and behavioral characteristics, and body weight was estimated by an experienced researcher. ${ }^{5,12,35}$ Average weight of all captured bobcats was estimated at $6.8 \mathrm{~kg}$. Animals were then given the recommended dose of $6 \mathrm{mg} / \mathrm{kg}$ of the tiletamine-zolazepam combination, taking extreme care to avoid potential overdosing (i.e., a total initial injection of $40 \mathrm{mg}$ or $0.4 \mathrm{ml}$ of the solution per individual was administered IM). For bobcats that exhibited light sedation signs and were still responsive to stimuli after the first injection, a second dose (or at occasion a third dose) of $1 \mathrm{mg} / \mathrm{kg}$ was administered to allow appropriate immobilization and safe handling.

The purpose of the immobilization procedure was to fit animals with a VHF radio collar (HLPM-3180M Wildlife Materials, Murphysboro, IL), for tracking of daily movements and monitoring of behavioral activities within their habitats. Total time for handling and collar fitting was between 20 and 40 minutes in all animals. As 
the procedure was not painful, animals were not put under deep anesthesia, which also facilitates recovery. Animals were followed by telemetry every 6 hours for 15 days per month, over the course of one year.

Age, sex and actual individual weight were ascertained once animals were anesthetized. Age was determined from mass and body size, and tooth wear. ${ }^{36}$ During handling, eyes of bobcats were protected from UV light and dust entry by a cotton cloth. A sterile ointment was also applied to avoid drying of the corneal surface. Sedation was monitored by recording of physiological parameters every 15 min (heart and respiratory rates, body temperature, Table 1), and by tracking the duration of the different stages of anesthesia. Induction time was considered from injection of the tiletamine - zolazepam solution until the onset of cataleptic anesthesia; Cataleptic anesthesia was the period where the animal was insensitive to external stimuli, which ended when individuals raised their heads. Finally, the recovery phase, was considered to start when bobcats were able to lift and hold up their heads, and to end when they could remain standing without showing any signs of drowsiness or lack of coordination. The sum of time taken to complete these three stages yielded the inability time (in minutes): ${ }^{37}$

IN (Induction time) + CA (Cataleptic Anesthesia time) + R (Recovery time) $=$ IT (Inability time) .

Physiological parameters were recorded until the animals became responsive and alert (an average of 3 records per individual per parameter were taken). Bobcats were kept under observation for as long as needed to ascertain complete recovery from the anesthesia. Once animals exhibited normal posture and reflexes, they were released from holding crates, and naturally returned to their habitat. All bobcats recovered from immobilization without the assistance of an antagonist.

\section{Data analysis}

Student's t- tests were used to compare physiological parameters between sexes during anesthesia.

\section{Results and discussion}

The commercial analgesic solution Zoletil ${ }^{\circledR}$ was administered according to manufacturer instructions (Virbac S.A., Carros, France 2003), using the recommended dose for bobcats $(6.0 \mathrm{mg} / \mathrm{kg}$ ). All animals survived the handling procedure, and no signs of sedation or post-sedation distress (dyspnea, seizures) were observed. Typical behavior in terms of stress and resistance to capture was presented by the eight individuals before anesthetic administration. According to the average estimated weight of individuals at $6.8 \mathrm{~kg}$, an initial dose of $40 \mathrm{mg}$ was administered to every bobcat. There were differences in induction time after anesthetic injection between animals (Table 1). Two bobcats (one female and one male) had a rapid induction time (2 min), going almost directly into a cataleptic state after sedative injection. The female bobcat remained in the cataleptic stage for 64 minutes, while the male stayed in this phase for 50 min (Table 1). 
Table 1. Weight, physiological parameters, and duration of anesthesia stages of captured bobcats immobilized with a tiletamine-zolazepam solution.

\begin{tabular}{|c|c|c|c|c|c|c|c|c|c|}
\hline \multicolumn{10}{|c|}{ Average (rate) } \\
\hline Bobcat & $\begin{array}{l}\text { Weight } \\
\text { (kg) }\end{array}$ & $\underset{(\mathrm{min})}{\text { IN }}$ & $\underset{(\mathrm{min})}{\mathrm{CA}}$ & $\underset{(m i n)}{R}$ & $\underset{(\mathrm{min})}{\mathrm{IT}}$ & $\begin{array}{l}\text { RT } \\
\left({ }^{\circ} \mathrm{C}\right)\end{array}$ & $\begin{array}{l}\text { Heartbeat } \\
/ / \mathrm{min}\end{array}$ & $\begin{array}{l}\text { Respiration } \\
/ / \mathrm{min}\end{array}$ & $\begin{array}{l}\text { Dose } \\
(\mathrm{mg})\end{array}$ \\
\hline Female & 6.0 & 2 & 64 & 25 & 89 & 38 & 156 & 40 & 40 \\
\hline Female & 8.0 & 5 & 66 & 19 & 85 & 38.05 & 184 & 36 & 45 \\
\hline Female & 8.0 & 15 & 35 & 55 & 90 & 38.6 & 180 & 40 & 50 \\
\hline Female & 7.5 & 15 & 55 & 35 & 90 & 38 & 180 & 40 & 40 \\
\hline Average & 7.8 & 9.25 & 55.00 & 33.50 & 88.50 & 38.16 & 175.00 & 39.00 & 43.75 \\
\hline $\begin{array}{l}\text { Standard } \\
\text { deviation }\end{array}$ & 0.95 & 6.75 & 14.17 & 15.78 & 2.38 & 0.29 & 12.81 & 2.00 & 4.79 \\
\hline Male & 7.6 & 5 & 52 & 68 & 120 & 38.9 & 180 & 30 & 45 \\
\hline Male & 7.0 & 15 & 30 & 40 & 70 & 39.3 & 153 & 55 & 50 \\
\hline Male & 9.5 & 20 & 20 & 60 & 80 & 38 & 200 & 40 & 45 \\
\hline Male & 7.2 & 2 & 50 & 55 & 105 & 37.85 & 180 & 28 & 40 \\
\hline Average & 7.83 & 10.50 & 38.00 & 55.75 & 93.75 & 38.51 & 178.25 & 38.25 & 45.00 \\
\hline $\begin{array}{l}\text { Standard } \\
\text { deviation }\end{array}$ & 1.14 & 8.43 & 15.58 & 11.79 & 22.87 & 0.70 & 19.29 & 12.34 & 4.08 \\
\hline Averaget $^{t}$ & 7.60 & 9.88 & 46.50 & 44.63 & 91.13 & 38.34 & 176.63 & 38.63 & 44.38 \\
\hline $\begin{array}{l}\text { Standard } \\
\text { deviation }\end{array}$ & 1.00 & 7.10 & 16.51 & 17.54 & 15.31 & 0.53 & 15.26 & 8.19 & 4.17 \\
\hline
\end{tabular}

CA: cataleptic anesthesia; IN: induction time; IT: inability time; R: recovery; RT: rectal temperature.

t Total.

\section{Induction}

The average induction time was 9.8 minutes and the cataleptic state lasted for 46.5 minutes. Awakening was gradual and peaceful in all bobcats and occurred at an average of 44.6 minutes after catalepsy (Table 1).

There were no differences between sexes regarding physiological parameter data: rectal temperature $(t=-0.806, P=0.479)$, respiratory rate $(t=106$, $\mathrm{P}=0.922)$, or heart rate $(\mathrm{t}=-.259, \mathrm{p}=.813)$ (Table 1$)$.

Dosage, sedation, and duration of stages of anesthesia are all critical to eliminate or decrease mortality and adverse effects of wild individuals during handling. Assessment of chemicals used for this practice is therefore paramount to understand potential impact on different animal species. Information on putative effects is of value for reliability and safety when handling wildlife.

The effects of a commercial tiletamine-zolazepam solution were evaluated at each stage of sedation in desert bobcats captured in the wild. Standard doses of $40 \mathrm{mg}(6.0 \mathrm{mg} / \mathrm{kg})$ were given to both males and females since visual weight estimations were similar for both sexes. Estimated weight was subsequently ascertained by using a scale in sedated animals: females $=7.37 \mathrm{~kg}$, males $=7.82 \mathrm{~kg}$. The administered anesthetic dose allowed for safe animal handling, permitting to complete the collar fitting procedure within 20 to 40 minutes. The average inability time for the captured cats was 91 minutes. This period is relatively short compared 
to other studies conducted with the same sedative in wild felids, where IT for nine ocelots (Leopardus pardalis) in southern Texas using a dose of $5.05 \mathrm{mg} / \mathrm{kg}$, was reported to last 250 minutes, even if ocelot average weight was greater $(9.2 \mathrm{~kg})$ to that found for the bobcats in this study. ${ }^{13}$ Also, an IT of 104 minutes was reported for leaner leopard cats (Prionailurus bengalensis, $2.7 \mathrm{~kg}$ ) in Thailand. ${ }^{38}$ For the purposes of this study, the 91 minute IT period was also deemed adequate as to avoid stress or harm for the bobcats. Shorter IT periods had been reported when using a combination of ketamine hydrochloride and xylazine: 64 minutes in North Carolina bobcats, ${ }^{11} 59.1 \mathrm{~min}$ in Texan bobcats, ${ }^{20}$ and $69 \mathrm{~min}$ in Iberian lynxes (Lynx pardinus). ${ }^{23}$ However, 9\% of the 31 wild Iberian lynxes in this latter study presented chemical induced seizures, ${ }^{23}$ which were not observed in any of the bobcats sedated with tiletamine-zolazepam combination in this study.

Telemetry data taken through fitted radio collars (with at least 60 detections throughout the one-year monitoring period) showed that all handled bobcats in this study displayed normal behavior in terms of movement, resting and feeding within their habitat area. This suggest that there were no apparent ulterior adverse effects of sedation and handling.

\section{Conclusions}

An adequate inability time that allowed completion of collar fitting procedures in wild desert bobcats without the associated risk of extended anesthetic states, lack of complications during anesthesia, and a return to stable body conditions was achieved using a commercial tiletamine hydrochloride and zolazepam hydrochloride solution at a $6 \mathrm{mg} / \mathrm{kg}$ dose. Sedated animals were returned to the wild after handling and monitored by telemetry for at least 60 times over the course of one year in their natural habitats. All animals were alive and displaying apparent normal behavior by the completion of the observation year, tracked movements indicating thriving individual performance. Hence, the anesthetic protocol and handling procedures used in this study is safe and suitable for short-term immobilization of Sonoran Desert bobcats. 


\section{Acknowledgements}

We wish to thank Abelino Cota-Castro, Victor Ortiz-Avila, Antonio Rodríguez, Bruno Granados, and Enrique Cota for field work assistance, and Joshua James Parker for English editing of the manuscript.

This work was supported by a SEP-CONACYT México grant (R.R.E., 155956) and a doctoral fellowship from CONACyT México (GRF, 117791).

\section{Conflicts of interest}

The authors declare no conflict of interest related to this report.

\section{Author contributions}

R. R. E.: logistic support and manuscript revision.

L. A. T. C.: field animal support.

\section{References}

1. Baldwin JR, Winstead JB, Hayden-wing LD, Kreeger TJ, Dzialak MR. Field sedation of coyotes, red foxes, and raccoons with medetomidine and atipamezole. J Wildl Manage. 2008;72:1267-71.

2. Dong-Hyuk J, Jeong-Jin Y, Seong-Hoon S, Byeung-Cheul S, Seong-Chan Y. Immobilization of Asiatic black bears (Ursus thibetanus) with edetomidine-Zolazepam-Tiletamine in South Korea. J Wildl Dis. 2017; 53(3):636-41.

3. Lescano J, Quevedo M, Ramos M, Fernández V. Chemical restraint of captive Kinkajous Potos flavus (Schreber, 1774) (Carnivora: Procyonidae) using a ketamine, xylazine and midazolam combination and reversal with yohimbine. J Threat Taxa. 2016; 8(14): 9610-8

4. Wolfe LL, Goshorn CT, Baruch-Mordo S. Immobilization of black bears (Ursus americanus) with a combination of butorphanol, azaperone. J Wildl Dis. 2008;44:748-52.

5. Way JG, Ortega IM, Auger PJ. Eastern coyote home range, territoriality and sociality on urbanized Cape Cod. Northeast Wildl J. 2002;57:1-18.

6. Cattet MRL, Caulkett NA, Polischuk SC, Ramsay MA. Anesthesia of polar bears (Ursus maritimus) with Zolazepam-Tiletamine, medetomidine-ketamine, and medetomidine-Zolazepam-Tiletamine. J Zoo Wildl Med. 1999;30:354-60.

7. Stander PE, Morkel PVB. Field immobilizations of lions using dissociative anesthetics in combination with sedatives. Afr J Ecol. 1991;29:137-48.

8. Wright JM. Ketamine hydrochloride as a chemical restraint for selected small mammals. Wildl Soc Bull. 1983;11:76-7.

9. Bailey TN. Immobilization of bobcats, coyotes, and badgers with phencyclidine hydrochloride. J Wildl Manage. 1971;35:847-9.

10. Svorc P, Bacova I, Svorc P Jr, Monika N, Gresova S. Zoletil anaesthesia in chronobiological studies. Biol Rhythm Res. 2015;47:103-10.

11. Rockhill AP, Chinnadurai SK, Powell RA, DePerno CS. A comparison of two chemical immobilization techniques for bobcats (Lynx rufus). J Zoo Anim Med. 2011;44:580-5.

12. Burton MA, Perez NS, Tovar ChC. Bobcat ranging behavior in relation to small mammal abundance on Colima volcano, México. An Inst Biol Univ Nac Autón México Zool. 2003;74:67-82. 
13. Shindle DB, Tewes ME. Immobilization of wild ocelots with Tiletamine and Zolazepam in southern Texas. J Wild Dis. 2000;36:546-50.

14. Deem SL, Karesh WB. The Jaguar Health Program Manual. Jaguar Conservation Program, Wildlife Conservation Society. Bronx, New York; 2001. Disponible en: http://www.savethejaguar.com/fieldvet health manual.pdf. p. 1-45.

15. Broomhall LS, Mills MGL, Du Toit JT. Home range and habitat use by cheetahs (Acinonyx jubatus) in the Kruger National Park. J Zool. 2003;261:119-28.

16. Rucker RA, Kennedy ML, Heidt GA, Harvey MJ. Population density, movements, and habitat use of bobcats in Arkansas. Southwest Nat. 1989;34:101-8.

17. Kreeger TJ. Handbook of wildlife chemical immobilization. Laramie, Wyoming: International Wildlife Veterinary Services; 1996.

18. Lin J, Shih C, Kaphle K, Wu L, Tseng W, Chiu J, et al. Acupuncture e ects on cardiac functions measured by cardiac magnetic resonance imaging in a feline model. Evid Based Complementary Altern Med. 2010;7:169-76.

19. Nielsen CK, Woolf A. Spatial organization of bobcats (Lynx rufus) in southern Illinois. Amer Midl Naturalist. 2001;146:43-52.

20. Beltran JF, Tewes ME. Immobilization of ocelots and bobcats with ketamine hydrochloride and xylazine hydrochloride. J Wildl Dis. 1995;31:43-8.

21. Lindzey FG, VanSickle WD, Laing SP, Mecham CS. Cougar population response to manipulation in southern Utah. Wild Soc Bull. 1992;20:224-7.

22. Pond BD, O'Gara BW. Chemical immobilization of large mammals. En: Bookout $T A$, ed. Research and management techniques for wildlife and habitats, 5th ed. Bethesda, Maryland: The Wildlife Society; 1996. p. 419-44.

23. Ferreras $\mathrm{P}$, Aldama JJ, Beltrán JF, Delibes M. Immobilization of the endangered Iberian lynx with xylazine- and ketaminehydrochloride. J Wildl Dis. 1994; 30:65-8.

24. Zoetis SRL. Productos-Especies/Perros/Zelazol. Argentina. 2013-2020. Disponible en: https://ar.zoetis.com/products/caninos/zelazol.aspx

25. King JM, Bertram BCR, Hamilton PH. Tiletimine and Zolazepam for immobilization of wild lions and leopards. J Am Vet Med Assoc. 1977;171:894-8.

26. Stirling I, Spencer C, Andriashek DS. Immobilization of polar bears (Ursus maritimus) with Telazol in the Canadian Arctic. J Wildl Dis. 1989;24:159-68.

27. Ryan CW, Vaughan MR, Meldrum JB, Duncan RB, Edwards JW. Retention time of telazol in black bears. J Wildl Manage. 2009;73:210-3.

28. Collins DP, Harveson LA, Ruthven DC. Morphological characteristics and effects of telazol on American badgers in South Texas. Tex J Agr Nat Rec. 2013;26:25-31.

29. Conforti VA, Cascelli de Azevedo FC, De Oliveira Henriques OP, De Moraes W, Deddens JA. Chemical restraint of free-ranging South American coatis (Nasua nasua) with a combination of tiletamine and zolazepam. J Wildl Dis. 2017;53:140-3.

30. Corral JA, Medina-García G, Meza-Sánchez R, Díaz-Padilla G, Serrano-Altamirano V. Estadísticas climatológicas básicas del estado de Baja California Sur, periodo 1961-2003. Centro de Investigación Regional del Noroeste. México: SAGARPA-INIFAP; 2006. 
31. INEGI. Perspectiva estadística. Baja California Sur. Dirección General de Geografía y Medio Ambiente. Aguascalientes, México; 2012. Disponible en: https://www. inegi.org.mx/contenidos/transparencia/contenidos/doc/inf2012.pdf

32. Wiggins IL. Flora of Baja California. Stanford: Stanford University Press; 1980.

33. Riley SD, Sauvajot RM, Fuller TK, York EC, Kamradt DA, Bromley C, et al. Effects to urbanization and habitat fragmentation on bobcats and coyotes in southern California. Biol Conserv. 2003;17:566-76.

34. Animal Care and Use Committee. Guidelines for the capture, handling, and care of mammals as approved by the American Society of Mammalogists. J Mammal. 1998;79:1416-31.

35. Travaini A, Delibes M. Immobilization of free ranging red foxes (Vulpes vulpes) with Tiletamine hydrochloride and Zolazepam hydrochloride. J Wildl Dis. 1994;30:589-91.

36. Crowe DM. Aspects of aging, growth, and reproduction of bobcats from Wyoming. J Mammal. 1975;56:177-98.

37. Boever WJ, Holden J, Kane KK. Use of TelazolTM (Cl-744) for chemical restraint and anesthesia in wild and exotic carnivores. Vet Med Sm Anim Clin. 1977;72:1722-5.

38. Grassman, LI Jr, Austin SC, Tewes ME, Silvy NJ. Comparative immobilization of wild felids in Thailand. J Wildl Dis. 2004;40:575-8. 